\title{
К ВОПРОСУ О БАЗИСНЫХ ПОДХОДАХ РЕГУЛИРОВАНИЯ ТРАНСГРАНИЧНОЙ ЭЛЕКТРОННОЙ ТОРГОВЛИ В РОССИЙСКОЙ ФЕДЕРАЦИИ
}

\author{
(c) 2019 Сеидова Марина Райфудиновна \\ аспирант, кафедра торгового дело \\ Российский экономический университет имени Г.В. Плеханова \\ Москва, Стремянный переулок, д.36 \\ E-mail: msadyki@gmail.com
}

В статье рассматривается современное состояние развития трансграничной электронной торговли в Российской Федерации и возможные методы ее регулирования в свете общемировых подходов и перспектив. Также проводится анализ изменений в мировой экономике, которые определенным образом отразятся на методах регулирования в среднесрочной и долгосрочной перспективах. Проанализированы возможные экономические тренды. Ключевым фактором развития трансграничной электронной торговли определено создание условий для благоприятного инвестиционного климата для предпринимателей и комфортной потребительской среды для покупателей..

Ключевые слов: электронная торговля, электронная коммерция, трансграничная электронная торговля, интернет-торговля.

Актуальность исследований, связанных с определением перспективных направлений развития в сфере электронной торговли обусловлена трансформацией традиционных рынков. Электронная торговля - один из немногих динамично развивающихся сегментов рынка, объем которого продолжает расти в среднем на 30\% в год, начиная с 2011 года, несмотря на снижение реально располагаемых денежных доходов населения и индекса физического объема оборота розничной торговли, наблюдаемых на протяжении 2014-2017 гг.

Феномен электронной торговли имеет радужные перспективы с экономической точки зрения. Темпы роста рынка электронной торговли прежде всего обусловлены темпами проникновения Интернета. По данным Internet World Stats, по состоянию на 31 декабря 2017 года около 4,2 млрд. человек в мире пользуется Интернетом, количество интернет-пользователей по сравнению с 2000 годом выросло в 12 раз. Почти 3 млрд. пользователей Интернета человек из 20 стран, преимущественно развивающихся (Китай, Индия, Бразилия, Индонезия, Нигерия, Мексика), так и развитых (США, Япония, Германия, Великобритания, Франция, Италия). Российская Федерация по количеству интернет-пользователей на седьмом месте".

В связи с тем, что в Российской Федерации создание терминологии и релевантной и детализированной государственной статистики в сфере электронной торговли и находится на стадии формировании, практически все данные основаны на экспертных оценках и результатах социологических и заказных аналитических исследований, в основе которых заложены различные методологические подходы.

Государственная статистика розничной электронной торговли выражается единственным показателем: «доля продаж через Интернет в общем объеме оборота розничной торговли», составляемым на основе сведений о производстве и отгрузке товаров и услуг (рисунок 1). По итогам 2017 года значение этого показателя составило 1,3\%, то есть объем внутренней розничной электронной торговли в Российской Федерации составил в 2017 году 309,4 млрд. руб. Однако данная статистика не учитывает растущие объемы трансграничной электронной торговли.

Учитывая трансграничный характер интернет сети наряду с электронной торговлей, становится очевидным, что вопросы электронной торговли нецелесообразно рассматривать в отрыве от импорта по каналам электронной торговли и зарубежного законодательства.

Электронная торговля является инструментом, обеспечивающим потребителям (физическим и юридическим лицам) на территории Российской Федерации физическую и ценовую доступность всего спектра товаров, производимых в России и мире.

В связи с отсутствием унифицированной

* https://www.internetworldstats.com/top20.htm 


\section{Доля продаж через Интернет в общем объеме оборота розничной торговли (процент, значение показателя за год)}

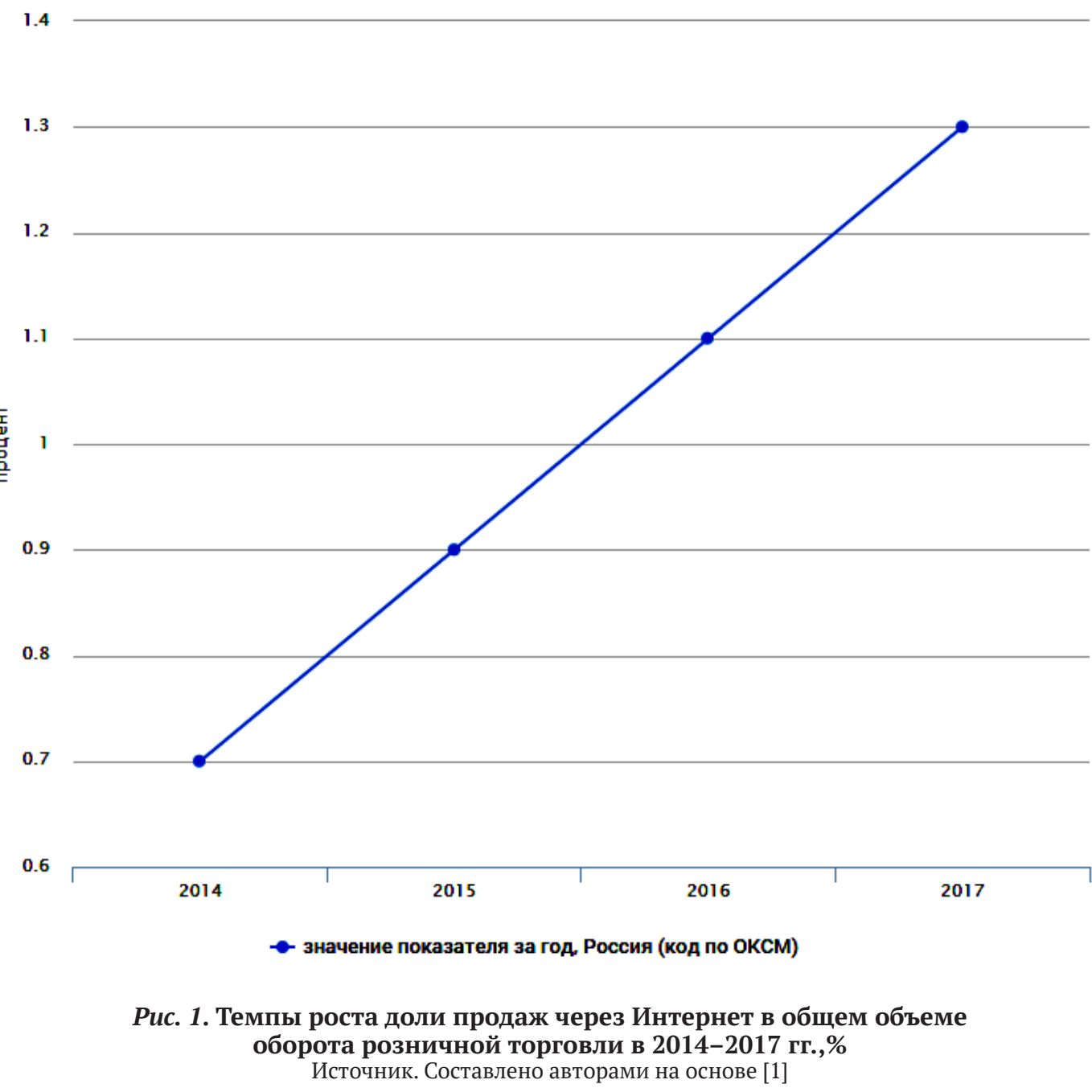

терминологии в целях настоящей публикации под термином «электронная торговля» следует понимать форму торговли, осуществляемой с использованием информационных систем, информационно-коммуникационной сети интернет или иных коммуникационных процедур посредством электронных транзакций в сети Интернет или иных коммуникационных сетях. При этом, платежи, доставка товара или оказание услуги могут осуществляться как электронный путем, так и иным.

Под термином «трансграничная электронная торговля» следует понимать электронную торговлю между участниками сделки, находящимися в различных юрисдикциях, одна из которых находится на территории Российской Федерации.

В настоящее время в Российской Федерации к отношениям в области электронной торговли применяются общеотраслевые нормы. Прежде всего, это нормы Гражданского кодекса Российской Федерации, Гражданского процессуального кодекса Российской Федерации, Арбитражного процессуального кодекса Российской Федерации, нормативно-правовые акты Центрального банка Российской Федерации, регулирующие сделки (в том числе с использованием электронных документов и скрепленные электронной подписью), предпринимательскую деятельность и электронные расчеты.

K трансграничной электронной торговле также применяются аналогичные традиционным внешнеторговым отношениям нормы Таможенного кодекса Таможенного союза.

Анализ существующих источников статистических данных показывает, что ежегодно проис- 
ходит постепенный рост электронной торговли, в том числе за счет гиперактивного роста трансграничной торговли.

По данным экспертов, в 2018 году оборот интернет-торговли в России, составил около 1,29 трл руб. Кроме того, существуют прогнозы, что к 2024 году рынок е-сommerce России вырастет до 3,49 трлн. руб. в 2024 году [1].

Для оценки уровня развития электронной торговли в России и его потенциала достаточно сопоставить долю электронной торговли в общем объеме оборота розничной торговли в ряде стран (Великобритания, Германия, Китай, Финляндия, США), где она составляет от $10 \%$ до $20 \%$.

По данным Всемирного почтового союза и отчетов национальных почтовых операторов, в Российской Федерации один из самых низких показателей покупок в сфере электронной торговли $-1,7$ покупки на душу населения в год (рисунок 2).

Катализатором стремительного роста трансграничной электронной торговли послужил не спрос со стороны потребителя, а предложение новой модели электронной торговли в виде экосистемы маркетплейса [4, с. 38].

Стремительный рост интернет-торговли способствует развитию национального логистического оператора. С 2015 года значительно выросла доля покупателей, которые воспользовались доставкой «Почты России», относительно тех, кто выбирал курьерскую доставку.

Таким образом, предложения по регулированию трансграничной электронной торговли должны соответствовать рыночным реалиям, и государственный аппарат, прибегая к «упорядочению» интернет-торговли должен четко следовать принципу: «Во-первых, не навреди».

Введение крайне высоких заградительных пошлин на товары, приобретаемые посредством трансграничной электронной торговли может привести к:

- сокращению сегмента интернет-торговли (одному из немногих бурно растущих секторов экономики);

- уменьшению предпринимательской активности внутри страны, в том числе сокращению заказов «Почты России», других логистических и сервисных структур;

- очень существенному ухудшению потребительского климата и уменьшению комфорта для потребителей. Граждане очень негативно воспринимают информацию СМИ о возможных ограничениях их покупок в зарубежных интернет-магазинах.

Посредством трансграничной торговли в России по большей части приобретаются недорогие и малогабаритные предметы (небрендовая «мелочевка»), производство и реализация которых не представлена на российском рынке. При этом доставка из-за рубежа занимает достаточно продолжительное время.

Следует отметить, что на оборот розничной торговли в денежном выражении в 2016-2017 гг. в значительной степени влияли такие факторы, как: индекс потребительских цен (который в 2017 году составил 103,7\% против 105,4\% в

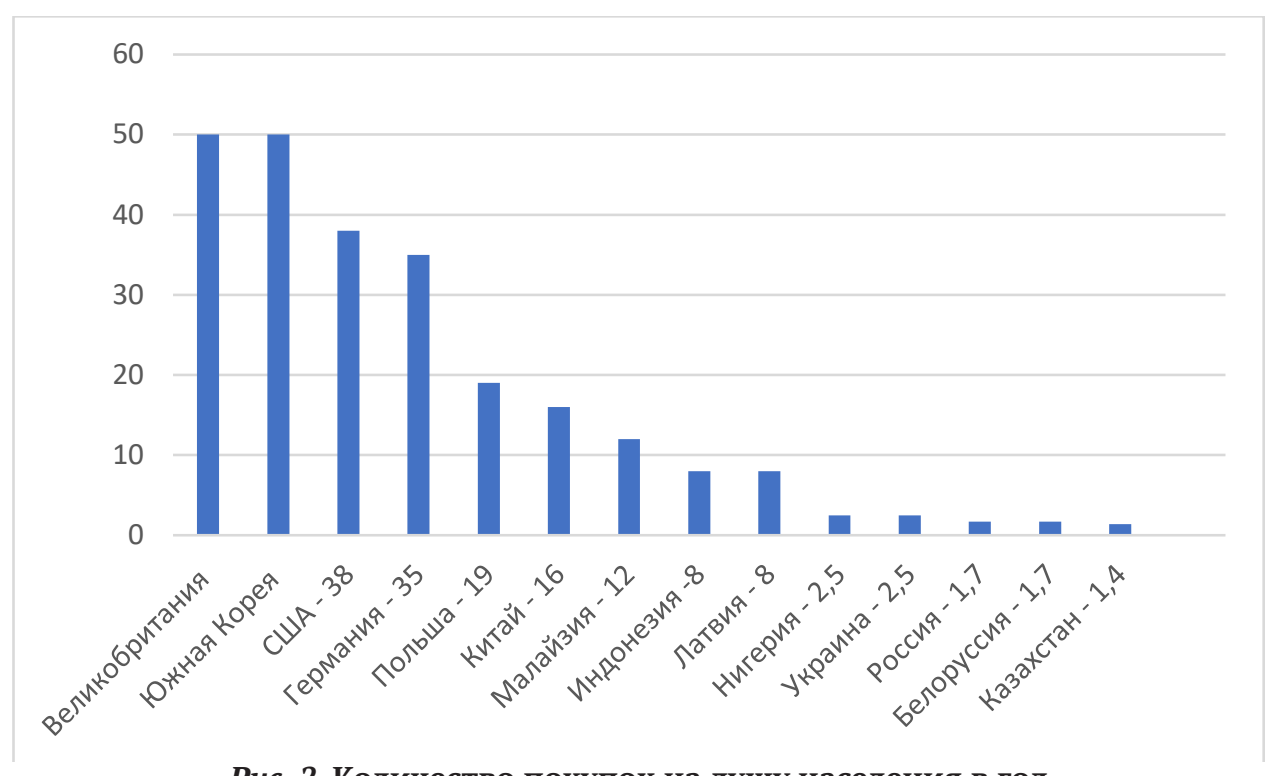

Puc. 2. Количество покупок на душу населения в год 
2016 г.), низкий уровень реальной заработной платы и реальных доходов населения (таблица 1), а также объёмов потребительского кредитования на фоне продолжения девальвации рубля и сохранении инфляционных процессов.

В свою очередь, многими экспертами отмечается низкая эффективность российских интернет-компаний. В целях обеспечения конкурентоспособности с зарубежными интернет-магазинами рекомендуется улучшить менеджмент, обеспечивать конкурентные цены, высокую конверсию заказов. По данным исследований, только 5\% российских интернет-магазинов качественно высчитывают стоимость обработки одного заказа, $10 \%$ интернет-магазинов опираются на качественную управленческую отчетность.

Вместо «закручивания гаек» относительно трансграничной торговли целесообразнее развивать, оптимизировать российский интернет-бизнес, к примеру, за счет широкого применения безналичных платежей, эффективного использования российскими компаниями аналитических инструментов и систем автоматизации, подготовки качественных кадров в сфере электронной торговли, развития уровня оказания логистических услуг и др.

На наш взгляд, в настоящее время необходимы меры не по ограничению электронной торговли, а по её развитию. В первую очередь, необходимы меры по облегчению ведения этого вида бизнеса внутри страны и существенному упрощению и удешевлению экспорта российских товаров посредством электронной торговли.

Развитие трансграничной торговли имеет в свою очередь экономический эффект, влияя на рост сопряженного рынка логистических услуг («Почта России» и другие операторы) и обслуживающих их компаний. Поэтому любые ограничения в этой сфере немедленно ударит по этим сегментам российского бизнеса. Применение предлагаемой рядом экспертов систе- мы регулирования трансграничной торговли со снижением порога беспошлинного ввоза и НДС регистрацией приведет к стагнации рынка логистических услуг и обслуживающих компаний.

В этой связи необходимо, не уменьшая предпринимательской активности по ввозу товаров в Россию посредством электронной торговли, сосредоточиться на увеличении сегмента экспорта товаров посредством интернета.

Например, чтобы открыть доступ к международному рынку товаров российских производителей повседневной одежды и обуви, осенью 2015 года Минпромторгом России был запущен совместный интернет-проект с крупнейшим в мире интернет-магазином Aliexpress.

По своему масштабу проект не имел аналогов, так как ранее крупнейшая торговая площадка сотрудничала преимущественно с китайскими производителями.

Согласно условиям проекта для отечественных производителей подключение к проекту бесплатно. В каталоге AliExpress товары из России отмечены триколором: «сделано в России». Кроме того, российским товарам был отдан приоритет в поиске. В результате реализации проекта российские производители смогли получить возможность в кратчайший срок и с минимальными затратами создать онлайн-магазин высокого уровня с огромным пакетом рекламной поддержки, рекордным количеством посетителей и свободным доступом на международный рынок онлайн-ритейла. География первой сотни участников проекта - производителей насчитывала 28 субъектов Российской Федерации.

Важно отметить, что внутри Европейского Союза (а это 28 стран) беспошлинный лимит отсутствует. В Европейском Союзе, кроме некоторых товаров, например, автомобили, можно заказывать на любую сумму из любой страны ЕС абсолютно беспошлинно.

В Великобритании, по данным Ассоциации магазинов электронной торговли IMRG, доля

Таблица 1. Основные показатели, характеризующие уровень жизни населения в 2016-2017 гг.

\begin{tabular}{|l|c|c|c|}
\hline \multicolumn{1}{|c|}{ Показатели } & $\begin{array}{c}2017 \text { г., } \\
\text { руб. }\end{array}$ & $\begin{array}{c}2017 \text { г., } \\
\text { в \% к 2016 г. }\end{array}$ & $\begin{array}{c}2016 \text { г., } \\
\text { в к 2015 г. }\end{array}$ \\
\hline Денежные доходы (в среднем на душу населения), руб. & 31475 & 102,4 & 100,9 \\
\hline Реальные располагаемые денежные доходы & - & 98,3 & 94,2 \\
\hline $\begin{array}{l}\text { Среднемесячная заработная плата работников организаций, } \\
\text { - номинальная }\end{array}$ & 39085 & 107,2 & 107,9 \\
\hline - реальная & - & 103,4 & 100,8 \\
\hline
\end{tabular}

Источник. Составлено авторами на основе [1] 
трансграничной торговли из Китая составляет всего 25\% от общего объема, что значительно ниже, чем в России (70\%). Большая же часть покупок в Англии совершается беспошлинно из стран ЕС. Кроме того, в той же Великобритании установлен очень обширный перечень товаров, в отношении которого действует режим беспошлинного ввоза даже из тех стран, которые не подпадают под единое таможенное пространство ЕС.

Таможенная служба Великобритании HMRC (Her Majesty's Revenue and Customs) имеет механизмы, с помощью которых взимается и перечисляется НДС. Эти механизмы действуют в соответствии с Меморандумом о взаимопонимании (Memoranda of Understanding), подписанным с некоторыми зарубежными таможенными и почтовыми организациями. Страны, с которыми имеют договоренность с HRMC: Нормандские острова, Гонконг, Сингапур, Новая Зеландия.

Степень участия государства в электронной торговле должна быть сопряжено с общим посылом отказа от антиконкурентных установок.

Модель налогообложения электронной торговли в государствах-членах ЕАЭС на сегодняшний день активно прорабатывается или уже регламентирована определенным способом.

Решением Совета Евразийской экономической комиссии от 20 декабря 2017 г. № 107 «Об отдельных вопросах, связанных с товарами для личного пользования» предусмотрено поэтапное снижение стоимостных норм беспошлинного ввоза товаров для личного пользования, доставляемых перевозчиком на таможенную территорию ЕЭС и (или) пересылаемых в международных почтовых отправлениях на таможенную территорию ЕЭС:

- с 1 января 2019 г. по 31 декабря 2019 г. включительно - стоимость не превышает сумму, эквивалентную 500 евро, и (или) вес не превышает 31 кг в течение 1 календарного месяца в адрес одного физического лица (ставка таможенных пошлин, налогов: 30\% от стоимости, но не менее 4 евро за 1 кг веса в части превышения стоимостной и (или) весовой норм)

- с 1 января 2020 г.- стоимость не превышает сумму, эквивалентную 200 евро, и (или) вес не превышает 31 кг (ставка таможенных пошлин, налогов: $15 \%$ от стоимости, но не менее 2 евро за 1 кг веса брутто международного почтового отправления в части превышения стоимостной и (или) весовой норм).
При этом государства - члены ЕЭС могут устанавливать более жесткие, чем предусмотрено решением ЕАЭС, стоимостные, весовые и (или) количественные нормы, в пределах которых такие товары для личного пользования ввозятся на таможенную территорию ЕЭС без уплаты таможенных пошлин, налогов (подпункт «ж» пункта 1 Решения).

Ужесточение порога беспошлинного ввоза товаров для личного пользования и в международных почтовых отправлениях ниже, чем в странах ЕАЭС, приведет к осуществлению перелетов и перетеканию отправлений через страны ЕАЭС. Эта мера будет иметь экономический эффект, если будут гармонизированные ставки на территории всей таможенной территории ЕАЭС. Такие ставки отражены в решении Совета ЕЭС от 20 декабря 2017 г. № 107.

Снижать их радикальнее бессмысленно, так как к стимулированию производства, замещению товаров на российском рынке эта мера не приведет. Речь идет о товарах разных стоимостных категорий, которые сравнивать нельзя. Средний чек китайских интернет-магазинов 980 руб, российских интернет-магазинов - 6410 руб.

Кроме того, прежде чем снижать порог беспошлинного ввоза должен быть создан, протестирован и внедрен удобный онлайн-сервис оплаты сборов для граждан (по английскому аналогу).

Целесообразно на данном этапе разработать порядок уплаты налога на добавленную стоимость при реализации товаров иностранными организациями российским физическим лицам, не являющимся индивидуальными предпринимателями, с использованием сети Интернет. Модель должна предполагать постановку на учет в налоговых органах иностранной организации, реализующей с использованием сети Интернет товары российским физическим лицам, не являющимся индивидуальными предпринимателями, в целях уплаты налога на добавленную стоимость. Согласно модели местом реализации товаров иностранными организациями с использованием сети Интернет признается территория Российской Федерации в случае, если покупателем товара является российское физическое лицо. Налоговая база для целей применения НДС в отношении операций по реализации иностранными организациями товаров физическим лицам определяется как стоимость этих 
товаров, исчисленная исходя из фактических цен их реализации.

Вместе с тем в настоящее время при ввозе физическими лицами товаров для личного пользования взимание НДС осуществляется таможенными органами с использованием механизма уплаты таможенных платежей, установленного Соглашением о порядке перемещения физическими лицами товаров для личного пользования через таможенную границу таможенного союза и совершения таможенных операций, связанных с их выпуском.

В связи с этим в случае перехода на новую модель физическое лицо будет уплачивать соответствующую сумму налога, исчисленную по расчетной ставке, поставщику в цене товара, а также таможенные пошлины, налоги по единой ставке в размере 30 процентов, но не менее 4 евро за 1 килограмм таможенным органам при превышении нормы ввоза товаров.

При этом следует учитывать, что норма ввоза определяется таможенными органами по товарам, ввезенным за месяц в разрезе конкретного покупателя независимо от того, кто являлся продавцом товаров. В то же время конкретный продавец не обладает информацией о всех товаpax, ввезенных соответствующим покупателем.

Таким образом, принятие модель взимания НДС с иностранной организации приведет к двойному налогообложению НДС товаров, превышающих норму ввоза.

В отличие от электронных услуг, ввоз товаров на территорию Российской Федерации согласно таможенному законодательству администрируется таможенными органами. В этой связи разделение полномочий налоговых и таможенных органов может привести к размыванию контроля за исчислением и уплатой НДС и усложнению администрирования уплаты НДС по ввозимым товарам.

Кроме того, часть иностранных продавцов, реализующих товары через иностранную электронную торговую площадку, получает оплату непосредственно от покупателей. В связи с этим возникает необходимость постановки на учет значительного количества иностранных лиц, реализующих товары физическим лицам через Интернет, что, соответственно, усложнит контроль за правильностью исчисления НДС.

Налогообложение НДС товаров, приобретаемых у иностранных организаций через Интернет, приведет к расходам средств федерального бюджета на создание необходимой информационной, контрольной и административной системы российскими налоговыми и таможенными органами.

Минфином России совместно с ФТС России и «Почтой России» было заявлено о проведении эксперимента автоматизации платежей - coздание института уполномоченного оператора, когда третье лицо (почтовая служба) наделяется правом оплачивать таможенный сбор за покупателями через интернет-площадку. В таком случае покупатель смог бы увидеть и оплатить сумму пошлины сразу при заказе товара по интернету. Однако этот эксперимент не запущен из-за отсутствия нормативно-правового регулирования (технически эксперимент был подготовлен).

Сейчас для оплаты таможенно-приходного ордера (ТПО) покупатель должен посетить почтовое отделение дважды (один раз - для оплаты товара (если оплачивает через банк, то требуется еще визит в банк), второй раз - для получения посылки).

Это крайне неудобно для покупателей и создает нагрузку для почтовых отделений.

Не менее важным вопросом является расчет ожидаемого финансово-экономического эффекта, учитывающего необходимость администрирования модели трансграничной электронной торговли. По данным государственных органов принятие проекта постановления не повлечет дополнительных расходов из федерального бюджета. В то же время снижение порога увеличит нагрузку на таможенные органы за счет увеличения потока посылок.

По данным Ernst\&Young, при снижении порога беспошлинного ввоза стоимость администрирования налога может вырасти до 1 млрд. евро. Стоимость администрирования 1 посылки составляет до 16 евро.

Государственная роль в сфере регулирования электронной торговли, с учетом ее трансграничности и экстерриториальности, должна быть минимальной и прежде всего регламентироваться политикой обеспечения безопасной среды, формирующей базис для ее развития. Эта модель развития трансграничной электронной торговли является оптимальной ввиду текущих трансформационных процессов развития международной торговли.

Радикальное ужесточение торговых барьеров на текущем этапе развития трансграничной 
электронной торговли (такие как обнуление порога беспошлинного ввоза, установление высоких протекционистских пошлин) не приведет к положительному финансовому результату в форме прямо пропорционального увеличения сборов пошлин и сборов от стоимости поступаемых в международных почтовых отправлениях товаров.
Роль электронной торговли в развитии национальной и мировой экономики обусловливает необходимость постановки более глубоких задач, связанных с разработкой экономико-математических моделей и статистических показателей и соответствующих методик расчета и анализа для оценки развития трансграничной электронной торговли в России.

\section{Библиографический список}

1. Информация о социально-экономическом положении России, 2017 год / Официальный сайт Федеральной службы государственной статистики // http://www.gks.ru/ [Электронный ресурс]. Дата обращения: 18.10.2018.

2. Официальный сайт Ассоциации компаний интернет-торговли (АКИТ) // http://www.akit.ru. [Электронный ресурс]. Дата обращения: 18.10.2018.

3. Андерсон Р. Просто не стой на пути: как государство может помочь бизнесу в бедных странах/ пер. с англ. Е. Артемовой. Москва- Челябинск. 2016. 379 с.

4. Микитани X. Маркетплейс 3.0. Новый взгляд на торговлю в интернете от основателя Rakuten - одного из крупнейших интернет-магазинов в мире/ пер. с англ. Москва. 2014. 288 с.

5. Савельев А.И. Электронная коммерция в России и за рубежом: правовое регулирование. Москва. 2014. 543 c.;

6. Keira McDermott. Key business drivers and opportunities in cross-border ecommerce. Entering an omnichannel world, 2015. 